\section{Atypical clinical presentation of typical endoscopic finding of Bouveret's syndrome}
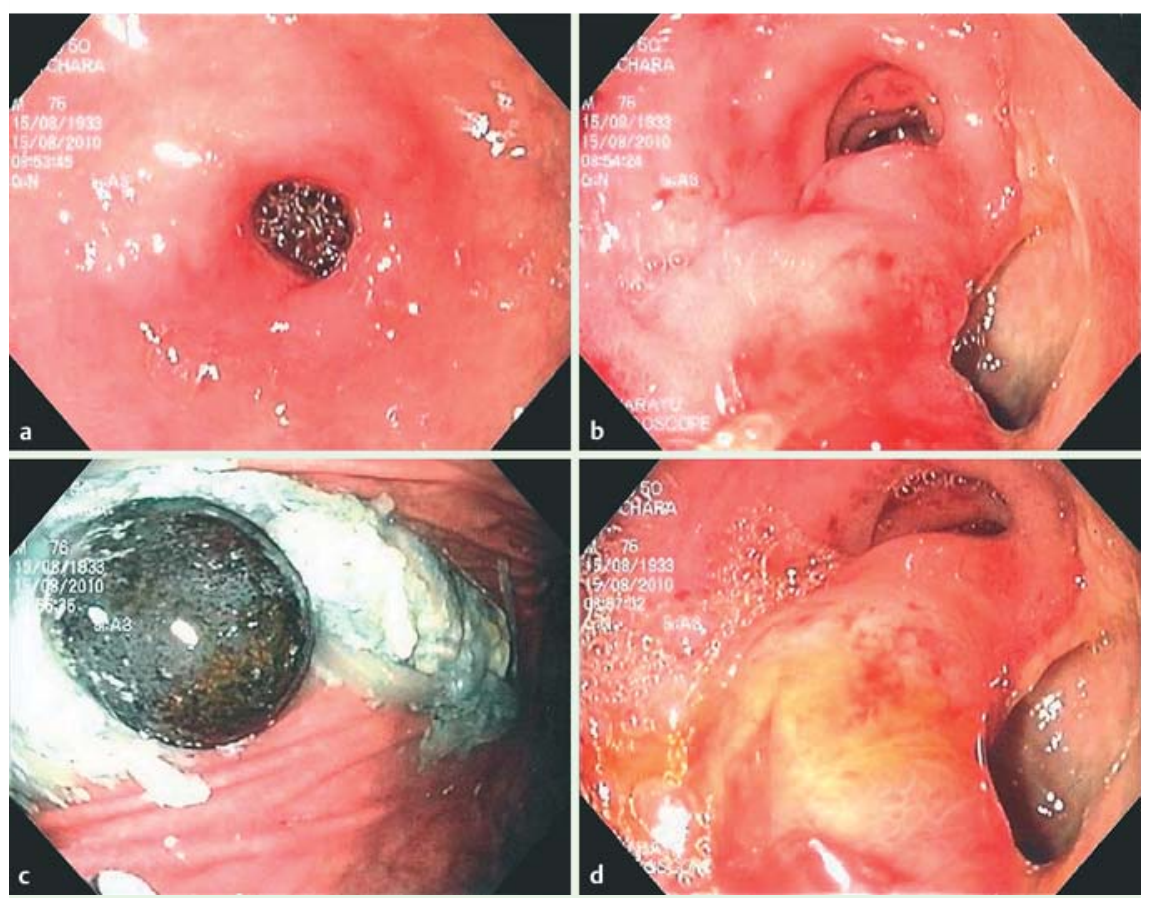

Fig. 1 Endoscopic view of gallstone a impacted in the duodenal bulb and $\mathbf{c}$ after it was removed. b, d Choledochoduodenal fistula.

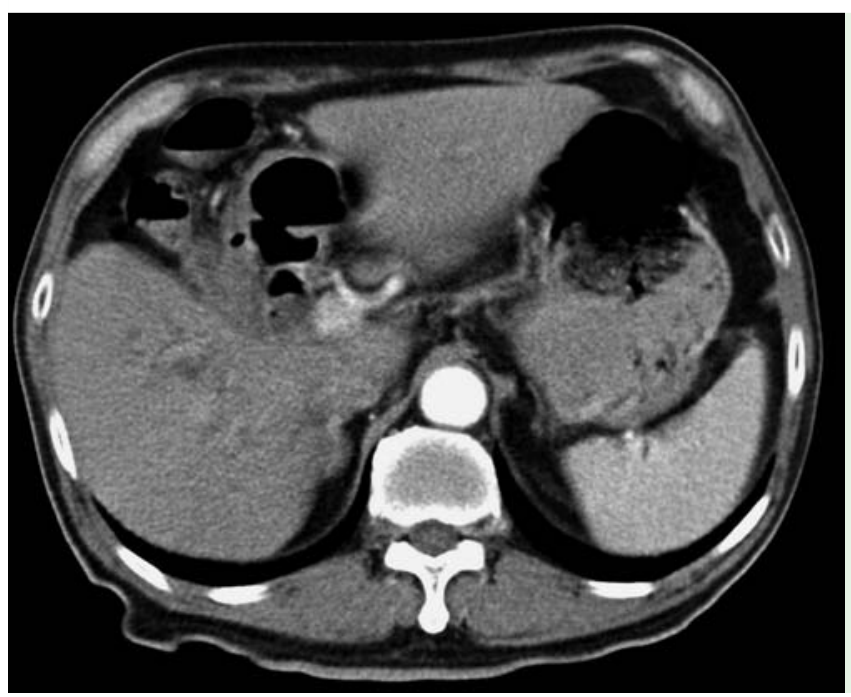

Fig. 2 Computed tomography (CT) scan showing the hypodensity tract which connected gallbladder and duodenum.

Bouveret's syndrome is a rare but recognizable condition which was first reported by Leon Bouveret in 1896 [1]. This syndrome is a clinical syndrome of gastric outlet obstruction due to gallstone impaction. Cappell et al. characterized the symptoms of Bouveret's syndrome: patients, usually older than 70 years, presented with abdominal pain (71\%), nausea, and vomiting (87\%), hematemesis (15\%), anorexia (13\%), and weight loss (14\%)
The stool was watery without any white blood cells or red blood cells. The patient underwent endoscopy to exclude internal malignancy. The esophagogastroduodenoscopy showed a large gallstone $2.5 \mathrm{~cm}$ in diameter ( Fig. 1) impacted in the duodenal bulb.

After the stone was removed endoscopically, there was a cholecystoduodenal fistula at the posterior wall of the duodenal bulb. The computed tomography (CT) scan ( Fig. 2) showed a hypodensity track which connected the gallbladder and duodenum.

The patient's diarrhea subsided after the endoscopy was performed. The patient underwent endoscopic retrograde cholangiopancreatography 1 week later, which demonstrated multiple common bile duct (CBD) stones with leakage of contrast media from the mid $\mathrm{CBD}$ to the first part of the duodenum. Finally, the patient underwent CBD stone removal with a Dormia basket and balloon retrieval catheter, and we planned for surgical correction.

Despite the fact that more than 300 cases of Bouveret's syndrome have been reported [3], subacute diarrhea has never been reported as one of the clinical presentations of Bouveret's syndrome. We think that the diarrhea in this case might be related to intestinal inflammation or colonic irritation from bile salts.

Endoscopy_UCTN_Code_CCL_1AB_2AZ_3AZ

Competing interests: None

\section{Prachayakul ${ }^{1,2}$, P. Aswakul ${ }^{2}$, U. Kachintorn ${ }^{1,2}$}

Division of Gastroenterology, Department of Internal Medicine, Siriraj Hospital, Mahidol University, Bangkok, Thailand

2 Vikit Viranuwatti Endoscopy Center, Siriraj Hospital, Mahidol University, Bangkok, Thailand

\section{References}

1 Alessabdro F, Pietro N, Antonio $M$ et al. A rare variant of gallstone ileus: Bouveret's syndrome. J Gastrointest Surg 2010; 14: $753-$ 755

2 Mitchell SC, Michael D. Characterization of Bouveret's syndrome: a comprehensive review of 128 cases. Am J Gastroenterol 2006; 101: 2139-2146

3 Cornel I, Raluca B, Nadin AH et al. Bouveret syndrome associated with acute gangrenous cholecystitis. J Gastrointestin Liver Dis 2008; 17: 87-90 
Bibliography

DOI $10.1055 / \mathrm{s}-0030-1256058$

Endoscopy 2011; 43: E55 - E56

(c) Georg Thieme Verlag KG Stuttgart . New York . ISSN 0013-726X

\author{
Corresponding author \\ P. Aswakul, MD \\ Vikit Viranuwatti Endoscopy Center \\ Siriraj Hospital \\ Mahidol University \\ Bangkok 10711 \\ Thailand \\ Fax: +66-2-4299672 \\ asawakul@gmail.com
}

